\title{
Tuning Emitting Color of Electroluminescent Devices Containing Tris(2-acyl-1,3-indandionate)aluminum(III) Complexes as Emitting Layers
}

\author{
Israel F. Costa, ${ }^{a}$ Jandeilson L. Moura, ${ }^{a}$ Rian E. Aderne, ${ }^{b}$ Harold C. Avila, ${ }^{b, c}$ \\ Marco Cremona, ${ }^{b}$ Hermi F. Brito, ${ }^{d}$ Maria Cláudia F. C. Felinto, ${ }^{e}$ Wagner M. Faustino ${ }^{a}$ \\ and Ercules E. S. Teotonio ${ }^{\circledR *} * a$
}

${ }^{a}$ Departamento de Química, Universidade Federal da Paraíba, 58051-970 João Pessoa-PB, Brazil

${ }^{b}$ Departamento de Física, Pontifícia Universidade Católica do Rio de Janeiro (PUC-Rio), 22453-970 Rio de Janeiro-RJ, Brazil

'Programa de Física, Universidad del Atlántico, Sede Norte Km 7, Vía Puerto Colombia, Atlántico, Colombia

${ }^{d}$ Departamento de Química Fundamental, Instituto de Química, Universidade de São Paulo, Av. Prof. Lineu Prestes, 2242, 05508-000 São Paulo-SP, Brazil

eInstituto de Pesquisas Energéticas e Nucleares (IPEN-CQMA), Av. Prof. Lineu Prestes, 2242, 05508-000 São Paulo-SP, Brazil

\begin{abstract}
In this study, a novel type of tris(2-acyl-1,3-indandione)-aluminum(III) coordination compounds of the general formula $\left[\mathrm{Al}(\text { acind })_{3}\right] \mathrm{H}_{2} \mathrm{O}$, where 2-acyl-1,3-indandione (acind), 2-acetyl1,3-indandione (aind), 2-benzoyl-1,3-indandione (bind), and 4-methyl-2-benzoyl-1,3-indandione (mbind), were synthesized and characterized by elemental analysis (CHN), Fourier transform infrared (FTIR) and nuclear magnetic resonance ( ${ }^{1} \mathrm{H}$ NMR) spectroscopies, thermal analysis (TG/DTG and DTA), and optical absorption spectroscopy in the UV-Vis region. These compounds present remarkably high green luminescence in powder and in thin-film forms. However, when these compounds are applied in glass/ITO/ $\beta-\mathrm{NPB} /$ spiro-2CBP/[Al(acind) $\left.)_{3}\right] / \mathrm{Al}$ and glass/ITO/ $/ \mathrm{N}-\mathrm{NPB} /$ $\left[\mathrm{Al}(\text { acind })_{3}\right] / \mathrm{LiF} / \mathrm{Al}$ electroluminescent devices, where spiro-2CBP is 2,7-bis(carbazol-9-yl)-9,9spirobifluorene and $\beta$-NPB is $N, N^{\prime}$-bis(naphthalen-2-yl)- $N, N^{\prime}$-bis(phenyl)-benzidine, the emission color tuned from green to red, reflecting a change from the direct charge recombination in the emitting layer of the $\left[\mathrm{Al}(\text { acind })_{3}\right]$ complexes to an exciplex-based emission in which $\left[\mathrm{Al}(\mathrm{acind})_{3}\right]$ complexes and spiro 2-CBP acted as acceptor and donor, respectively. These results suggest that $\left[\mathrm{Al}(\text { acind })_{3}\right]$ complexes have potential applications as molecular light converter materials for fabricating new electroluminescent devices.
\end{abstract}

Keywords: tris(2-acyl-1,3-indandionate)aluminum(III), OLED, red and green light emitting, tuning emitting colors, electroluminescence

\section{Introduction}

Since 1987, when Tang and VanSlyke ${ }^{1}$ reported for the first time on the electroluminescent property of aluminum 8-hydroxyquinolinate complex $\left(\mathrm{Alq}_{3}\right)$ as both green emitter and electron-transporting material, studies on organic light-emitting diodes (OLEDs) have mainly focused on two features: $(i)$ understanding the transport and recombination of charges in electroluminescent devices based on small molecules, and (ii) development of new materials that can act efficiently as either an electron (ETL) or hole (HTL) transporting layer, or as an emitting layer. ${ }^{2-5}$ Although

*e-mail: teotonioees@quimica.ufpb.br
OLEDs have great potential application for flat panel displays and eco-friendly light sources, many of these systems present low internal and external quantum efficiencies.

It is well known that $25 \%$ of singlet and $75 \%$ of triplet excited states are formed in OLEDs upon charge recombination, in accordance with spin statistics. Generally, the triplet state $\left(T_{1}\right)$ undergoes efficient deactivation processes via nonradiative decay to the singlet ground state $\left(\mathrm{S}_{0}\right)$, at room temperature, which may drastically limit the internal quantum efficiency (IQE). Different strategies have been applied, however, to decrease the loss of energy, leading to new electronic devices with IQE that can reach $100 \%$, such as (i) the use of heavy ions in the organic emitting layer to increase radiative decay 
from phosphorescence phenomenon; ${ }^{6-8}($ ii) the use of rareearth coordination compounds that exhibit highly efficient intramolecular energy transfer from the triplet excited state of the ligand to the ${ }^{2 \mathrm{~S}+1} \mathrm{~L}_{\mathrm{J}}$ excited level of the metal; ${ }^{9-12}$ (iii) the exploitation of the up conversion triplet-triplet annihilation (TTA) process; ${ }^{13-16}$ and (iv) thermally activated delayed fluorescence (TADF) compounds. ${ }^{17-20}$

The TADF mechanism is operative when there is a very small overlap between lowest unoccupied molecular orbital (LUMO) and highest occupied molecular orbital (HOMO). This is generally found when donor and acceptor moieties are structurally separated and weakly coupled, which provides an intramolecular charge transfer feature to the electronic transition and a very small energy difference $\Delta \mathrm{E}_{\mathrm{S}-\mathrm{T}}$ between the low-lying singlet and the triplet excited states. Consequently, the triplet state may transfer thermally its energy to the singlet one. This singlet harvesting effect ${ }^{21}$ may contribute to generation of light using all singlet and triplet excitons produced by a charge recombination within the electroluminescent device.

However, designing a molecular species that fulfills the requirement for TADF and also minimizes the internal conversion rate is not an easy task. Alternatively, a TADF mechanism may be achieved by exploiting the intermolecular charge transfer mechanism via interaction between different donor and acceptor molecules. In exciplex-based OLEDs, these molecules may be mixed in the same layer or they may be deposited in successive layers.

Different types of molecular systems have been used in the intermolecular donor-acceptor structure to improve the external quantum efficiency (EQE) and to obtain highperformance TADF devices emitting light from blue to red regions. ${ }^{22}$ Typically, they are based on copper(I) complexes or organic compounds..$^{23-25}$

The transition metal ${ }^{26-28}$ and rare-earth ${ }^{29-31}$ coordination compounds with 2-acyl-1,3-indandione (acind) ligands have also acted as luminescence sensitizers in both photo and electroluminescence processes. ${ }^{32}$ Furthermore, recent studies have investigated the effect of p-linker length connecting donor and acceptor groups on several properties of cyclic $\beta$-diketones-1,3-indandiones, such as thermal, electrochemical, and spectroscopic properties. ${ }^{33}$ Experimental results have also revealed that frontier orbitals for 2-acyl-1,3-indandione (acind) ligands presenting methyl and phenyl donor groups are generally located at low energies. However, acind ligands containing aromatic substituent groups generally present HOMO at lower energies than those ones with aliphatic groups. Consequently, Al-(2-acyl-1,3-indandione) complexes may be used to obtain novel diode devices with tunable structures and properties different from those ones presented by devices based on traditional Al-hydroxyquinolinate derivative complexes as emitting layers. ${ }^{29-32}$

In this study, the synthesis, characterization, and luminescent properties of novel $\mathrm{Al}^{3+}$-complexes based on 2-acyl-1,3-indandionate ligands were investigated. The photoluminescent properties of the complexes were analyzed in both powder and film forms. The electroluminescent devices were fabricated in two different configurations: glass/ITO/ $\beta-\mathrm{NPB} / \mathrm{Al}(\text { acind) })_{3} / \mathrm{LiF} / \mathrm{Al}$ (NPB: $N, N^{\prime}$-bis(naphthalen-2-yl)- $N, N^{\prime}$-bis(phenyl)-benzidine, device 1) and glass/ITO/ $\beta$-NPB/spiro-2CBP/Al(acind) $)_{3} /$ $\mathrm{Al}$ (spiro-2CBP: 2,7-bis(carbazol-9-yl)-9,9-spirobifluorene, device 2), which exhibited red and green emission colors, respectively, under applied voltage.

\section{Experimental}

\section{Materials}

Acetone (99\%), benzoylketone (99\%) and 4-methylbenzoylketone (99\%) were purchased from Aldrich Co. and used after drying procedure with molecular sieve for a week. Sodium hydride (NaH, $60 \%$ dispersion in mineral oil), aluminum nitrate nonahydrate $\left(\mathrm{Al}\left(\mathrm{NO}_{3}\right) 9 \mathrm{H}_{2} \mathrm{O}, 99 \%\right)$, toluene $(99 \%)$ and ethanol $(99 \%)$ solvents were purchased from Tedia and used without previous treatment. The 2-acetyl-1,3-indandione (aind), 2-benzoyl-1,3-indandione (bind) and 2-(4-methyl)benzoyl1,3-indandione (mbind) ligands were synthesized from the reaction between phthalate ester and acetone, benzoylketone, and 4-methylbenzoylketone, respectively. ${ }^{34}$ Spiro-2CBP (2,7-bis(carbazol-9-yl)-9,9-spirobifluorene, 99\%) and $\beta$-NPB ( $N, N^{\prime}$-bis(naphthalen-2-yl)- $N, N^{\prime}$-bis(phenyl)benzidine, $99 \%$ ) were purchased from Luminescence Technology Corporation and used without additional purification.

\section{Instruments}

Fourier transform infrared (FTIR) spectra were recorded with a PerkinElmer model spectrum two apparatus from 400 to $4000 \mathrm{~cm}^{-1}$. Thermogravimetric (TG) curves were obtained with a Shimadzu thermal analysis instrument, model TGA $60 \mathrm{H}$, from 35 to $1000^{\circ} \mathrm{C}$ in a dynamic atmosphere of synthetic air with a constant heating rate of $10{ }^{\circ} \mathrm{C} \mathrm{min}^{-1}$. The nuclear magnetic resonance ( ${ }^{1} \mathrm{H}$ NMR) spectra were recorded on a $400 \mathrm{MHz}$ Varian NMR spectrometer. The photoluminescence study was conducted based on the excitation and emission spectra recorded at room temperature $(300 \mathrm{~K})$ by 
using the front-face data collection mode $\left(22.5^{\circ}\right)$ with a $450 \mathrm{~W}$ xenon lamp as the irradiation source coupled to the a SPEX-Fluorolog 2 instrument with double monochromators. Time-resolved emission spectra were recorded at liquid nitrogen temperature $(77 \mathrm{~K})$ using a $50 \mathrm{~W}$ pulsed Xe lamp, as excitation sources. Moreover, a photomultiplier (R928P PMT) at $950 \mathrm{~V}$ in the photoncount system was used as a detector. Electroluminescence spectra of the fabricated OLEDs were collected using a spectrofluorimeter from photon technology international (PTI) model quanta master 40 . The current-voltage (I-V) characteristic curves were measured simultaneously with the electroluminescence spectra. The Commission Internationale de l'Eclairage (CIE) color coordinate diagrams were calculated from the emissions spectra using SpectraLux v2.0 software. ${ }^{35}$

Cyclic voltammetry measurements were performed with the aim of determining the HOMO and LUMO of tris(2-acyl-1,3-indandionate)aluminum(III) complexes. The voltammograms were recorded with a compact stat potenciostat (Ivium technologies), using a three-electrode cell containing a platinum $(\mathrm{Pt})$ wire as the counter electrode, vitreous carbon as the working electrode, and an $\mathrm{Ag} / \mathrm{AgCl}$ electrode as the reference electrode. The experiments were performed in a scan rate of $50 \mathrm{mV} \mathrm{s}^{-1}$ and a current range with $10 \mu \mathrm{A}$. The tris(2-acyl1,3-indandionate)aluminum(III) complexes solution $\left(10^{-4} \mathrm{~mol} \mathrm{~L}^{-1}\right)$ contained tetrabutylammonium phosphorus hexafluoride $\left(\mathrm{TBAPF}_{6}\right)$ in anhydrous dichloromethane. The ferrocene complex was used as an internal reference to calibrate the system.

\section{Synthesis of 2-acyl-1,3-indandione ligands}

2-Acyl-1,3-indandione ligands were synthesized by the reaction between diethyl phthalate and acetone, benzoylketone or 4-methylbenzoylketone at the molar ratio of $1: 1$, according to the experimental procedure described in literature. ${ }^{29}$

Synthesis of tris(2-acyl-1,3-indandionate)aluminum(III) complexes

First, at room temperature $(300 \mathrm{~K})$, a solution of $25 \mathrm{~mL}$ of aluminum nitrate $(0.93 \mathrm{mmol})$ in ethanol was added dropwise to a stirred ethanolic solution $(150 \mathrm{~mL})$ containing $0.71 \mathrm{~g}(2.8 \mathrm{mmol})$ of 2-acyl-1,3-indandione ligands (acind), where acind: aind, bind, or mbind. Subsequently, the $\mathrm{pH}$ of the resulting solution was adjusted to approximately 7.0 with an ethanolic solution of $\mathrm{NH}_{4} \mathrm{OH}$. A yellow precipitate was obtained, as the base was added to the mixture, which was then filtered and washed with water and ethanol to remove the excess ligand molecules. Finally, the solution was dried under reduced pressure. Although the tris(2-acyl-1,3-indandionate)aluminum(III) coordination compounds are very soluble in several solvents (dichloromethane, chloroform, ethyl acetate, acetone, toluene, dimethylformamide, etc.), all attempts to obtain single crystals were unsuccessful. Anal. calcd. for $\mathrm{C}_{33} \mathrm{H}_{23} \mathrm{AlO}_{10}$ : C 65.35, H 3.82; found: C 65.37, H 3.60; IR $(\mathrm{KBr}) \vee / \mathrm{cm}^{-1} 1707,1612,1587,1570,1498,1468,1456$, 1431, 1417, 1362, 1350, 1301, 1176, 1151, 1076, 1024, 883, 808, 740, 711, 652, 601, 569, 538, 484, 436. Anal. calcd. for $\mathrm{C}_{48} \mathrm{H}_{29} \mathrm{AlO}_{10}$ : C 72.73, H 3.69; found: C 72.09, H 3.62; IR (KBr) v / cm ${ }^{-1} 1707,1612,1587,1570,1498$, 1468, 1456, 1431, 1417, 1362, 1350, 1301, 1176, 1151, 1076, 1024, 883, 808, 740, 711, 652, 601, 569, 538, 484, 436. Anal. calcd. for $\mathrm{C}_{51} \mathrm{H}_{35} \mathrm{AlO}_{10}$ : C 73.38, $\mathrm{H}$ 4.23; found: C 72.65, H 4.23; IR (KBr) v / $\mathrm{cm}^{-1} 3408,3066,1639,1614$, 1599, 1411, 1001, 808.

\section{OLED fabrication}

OLED devices containing tris(2-acyl-1,3-indandionate) aluminum(III), $\mathrm{Al}$ (acind) $)_{3}$, complexes as the active layer were prepared with two different configurations, depending on the organic molecule used as the hole-transporting layer: glass/ITO/ $\beta-\mathrm{NPB} / \mathrm{Al}$ (acind) ${ }_{3} / \mathrm{LiF} / \mathrm{Al}$ (devices $1 \mathrm{a}, 1 \mathrm{~b}$, and $1 \mathrm{c}$ ), and glass/ITO/ $\beta$-NPB/spiro-2CBP/Al(acind) $)_{3} / \mathrm{Al}$ (devices 2a, 2b, and 2c), where the letters a, b, and c refer to the $\mathrm{Al}(\text { aind })_{3}, \mathrm{Al}$ (bind) $)_{3}$, and $\mathrm{Al}$ (mbind) $)_{3}$ as emitting layers, respectively (Figures 1a and 1b). Prior to the device fabrications, ITO-coated glasses substrates were subsequently precleaned by ultrasonication with detergents, toluene degreasing, and pure isopropyl alcohol. Then, they were dried using a flux of nitrogen gas and transferred to a deposition chamber. For the devices $1 \mathrm{a}, 1 \mathrm{~b}$ and $1 \mathrm{c}$, the $\beta$-NPB was used as the hole-transporting layer, while the $\mathrm{Al}$ (acind) $)_{3}$ complexes were used as bifunctional materials behaving as both emitting and electron-transporting layers. These compounds were thermally evaporated consecutively onto cleaned ITO glass substrates (Figure 1c) with a deposition rate of $0.1-0.3 \mathrm{~nm} \mathrm{~s}^{-1}$. Finally, a $1 \mathrm{~nm}$ thick LiF film was deposited followed by deposition of $100 \mathrm{~nm}$ of aluminum cathode, using deposition rates of 0.1 and $1 \AA^{-1}$, respectively. For the devices $2 \mathrm{a}, 2 \mathrm{~b}$, and $2 \mathrm{c}$, an additional spiro-2CBP layer was deposited after the NPB one. All thin films of the complexes were prepared in a chamber under reduced base pressure around $1.7 \times 10^{-6}$ Torr.

The thickness of the layers was monitored in situ through a quartz crystal oscillator and confirmed with a profilometer measurement. The fabricated devices 
(a)

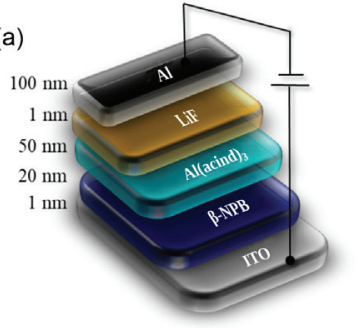

Device 1

(c)

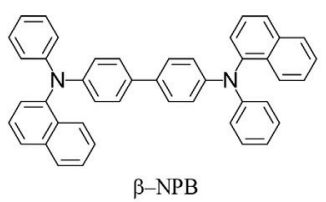

(b)
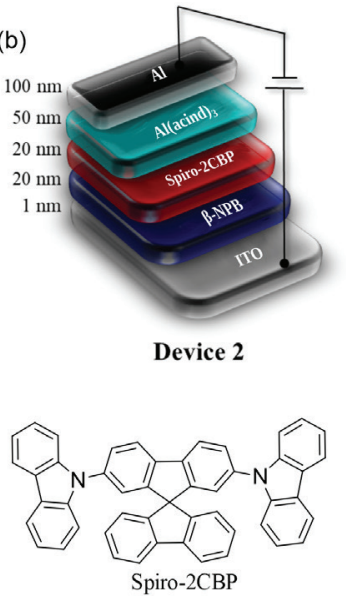

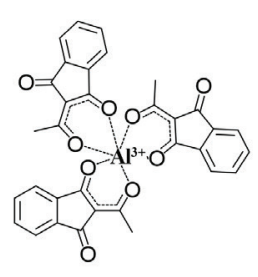

$\mathrm{Al}(\text { aind })_{3}$

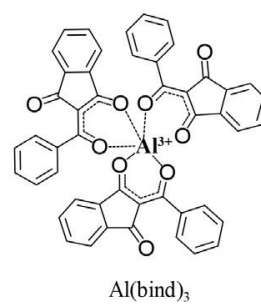

$\mathrm{Al}(\text { bind })_{3}$

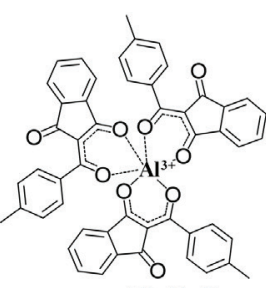

$\mathrm{Al}(\text { mbind })_{3}$
Figure 1. OLED configurations of the (a) device 1 and (b) device 2, and (c) structural formulae of the molecules used in the fabrication of OLEDs.

presented an active area of approximately $4 \mathrm{~mm}^{2}$ and operated in forward bias voltage, with ITO as the positive electrode and $\mathrm{Al}$ as the negative one. The two device structures are shown in Figures 1a and 1b.

\section{Results and Discussion}

\section{Characterization}

The elemental analysis data for the coordination compounds agree with the general formula $\mathrm{Al}(\text { acind })_{3}\left(\mathrm{H}_{2} \mathrm{O}\right)$, where acind ligand is aind, bind, or mbind. FTIR spectra for the $\mathrm{Al}^{3+}$-complexes show weak (ca. $3057 \mathrm{~cm}^{-1}$ ) and medium (ca. $2950 \mathrm{~cm}^{-1}$ ) absorption bands attributed to the aromatic and aliphatic $v(\mathrm{C}-\mathrm{H})$ stretching of the indandionate ligands, respectively (Supplementary Information (SI) section, Figure S1). It is also observed that strong bands around $1610 \mathrm{~cm}^{-1}$ assigned to $v(\mathrm{C}=\mathrm{O})$ coupled to $v(\mathrm{C}=\mathrm{C})$ stretching of the indandionate ligands are shifted to lower energies, as compared with those for free ligands, suggesting that these ligands are coordinated to the $\mathrm{Al}^{3+}$-complexes in chelating form. The absorption band around $1700 \mathrm{~cm}^{-1}$ may be assigned to the uncoordinated carbonyl group of the indandionate ligand. ${ }^{30} \mathrm{H}$ NMR spectra of the $\mathrm{Al}^{3+}$-complexes in deuterated chloroform show characteristic signals attributed to the hydrogen atoms of the coordinated ligands, which broaden and slightly shift as compared with those for free ligands, confirming the formation of the coordination compounds. Furthermore, in these spectra, their integrated intensity ratios remained almost unchanged, reinforcing the composition and formation of the complexes (SI section, Figure S2).

Thermogravimetric analysis (TGA) curves for $\mathrm{Al}^{3+}$-(indandionate) coordination compounds recorded under nitrogen atmosphere with a heating rate of $10^{\circ} \mathrm{C} \mathrm{min}^{-1}$ are shown in SI section, Figure S3. These curves exhibit a weight loss of ca. $2 \%$ in the temperature interval of $30-200{ }^{\circ} \mathrm{C}$, indicating the release of one non-coordinated water molecule. In addition, we observed three consecutive thermal decomposition processes in the range of $300-750{ }^{\circ} \mathrm{C}$, except for the $\mathrm{Al}(\text { bind })_{3}\left(\mathrm{H}_{2} \mathrm{O}\right)$ coordination compounds that exhibited an abrupt weight loss from 400 to $600{ }^{\circ} \mathrm{C}$. These results reveal that the substituent group plays an important role on the thermal decomposition of $\mathrm{Al}^{3+}$-(indandionate) coordination compounds. Furthermore, the anhydrous $\mathrm{Al}$ (bind) ${ }_{3}$ complex is the highest thermally stable compound. Finally, an uncompleted thermal decomposition until $900^{\circ} \mathrm{C}$ was observed for all the complexes.

Figure 2 shows TG curves for $\mathrm{Al}^{3+}$-(indandionate) coordination compounds recorded under synthetic air atmosphere. These curves exhibit similar profiles as those recorded under a nitrogen atmosphere (SI section, Figure S3), up to a temperature around $450{ }^{\circ} \mathrm{C}$ corresponding to the second thermal decomposition event. On the other hand, above this temperature, the system undergoes a complete decomposition, producing $\mathrm{Al}_{2} \mathrm{O}_{3}(2.7 \%)$. The final residue for the $\mathrm{Al}$ (bind) coordination compound is less than the calculated value (ca. 6\%), suggesting that the evaporation and the thermal decomposition processes occur at similar temperatures. The evaporation process at low temperature is very important for the fabrication of OLEDs. In addition, differential thermal analysis (DTA) curves present an

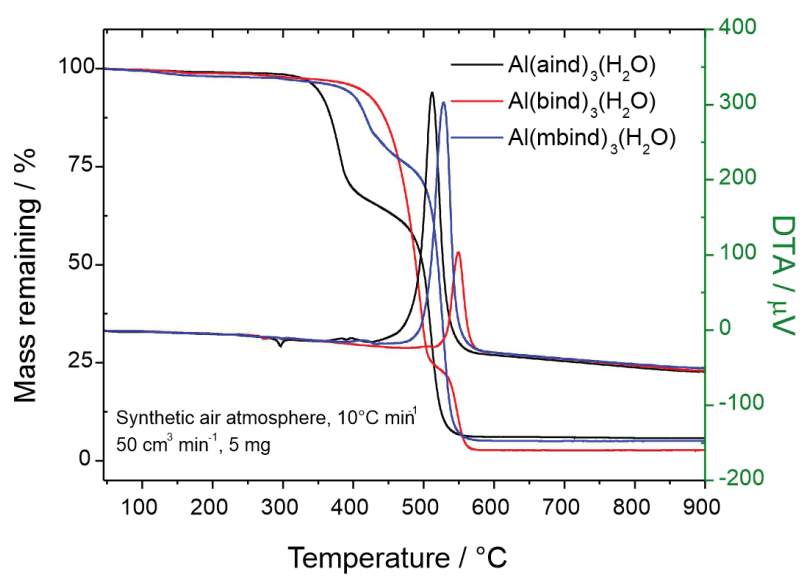

Figure 2. TGA and DTA thermograms of $\mathrm{Al}(\text { aind })_{3}\left(\mathrm{H}_{2} \mathrm{O}\right), \mathrm{Al}(\text { bind })_{3}\left(\mathrm{H}_{2} \mathrm{O}\right)$, and $\mathrm{Al}(\mathrm{mbind})_{3}\left(\mathrm{H}_{2} \mathrm{O}\right)$ compounds carried out in a dynamic synthetic air atmosphere at a heating constant rate of $10{ }^{\circ} \mathrm{C} \mathrm{min}^{-1}$. 
endothermic peak at 297,274 , and $299{ }^{\circ} \mathrm{C}$ associated to the melting point of $\mathrm{Al}$ (aind) $)_{3}, \mathrm{Al}$ (bind) $)_{3}$, and $\mathrm{Al}$ (mbind) anhydrous complexes, respectively. It is noteworthy that DTA curves recorded under synthetic air conditions are dominated by a highly exothermic peak corresponding to the second thermal decomposition process in comparison with those recorded under a $\mathrm{N}_{2}$ atmosphere.

Figure 3 shows the UV-Vis absorption spectra of $\mathrm{Al}^{3+}$-(indandionate) compounds recorded in the range of $200-800 \mathrm{~nm}$ in an acetonitrile solution $\left(1.0 \times 10^{-5} \mathrm{~mol} \mathrm{~L}^{-1}\right)$. As can be observed, the absorption spectra of compounds are characterized by three broad absorption bands with maxima at 230, 257, and $285 \mathrm{~nm}$, which can be assigned to the $\pi \rightarrow \pi^{*}$ transitions of the indandionate ligands. Furthermore, a low intense absorption band at $350 \mathrm{~nm}$ corresponding to $\mathrm{n} \rightarrow \pi^{*}$ transition is also observed. It is noteworthy that $\mathrm{UV}$-Vis spectra for $\mathrm{Al}(\text { bind })_{3}\left(\mathrm{H}_{2} \mathrm{O}\right)$ and $\mathrm{Al}(\text { mbind })_{3}\left(\mathrm{H}_{2} \mathrm{O}\right)$ coordination compounds exhibit an additional $\pi \rightarrow \pi^{*}$ transition at $337 \mathrm{~nm}$ owing to aromatic phenyl substituent moiety. The absorption spectra for $\mathrm{Al}(\text { acind })_{3}\left(\mathrm{H}_{2} \mathrm{O}\right)$ compounds in the form of film (SI section, Figure S4) display similar profiles as those for the respective systems in acetonitrile solutions. These spectroscopic results revealed that all complexes remain stable under evaporation condition used for the film deposition. Based on the TG curves, the thin films are formed by anhydrous $\left[\mathrm{Al}(\text { acind })_{3}\right]$ complexes, considering that the non-coordinated water molecule is released at low temperature. However, it is expected that there would be no significant interference of the non-coordinate water on either the spectroscopic or the electronic properties of the complexes.

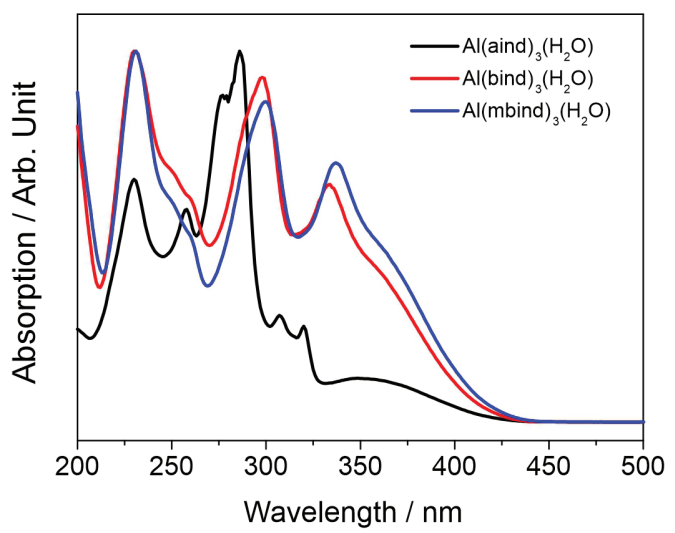

Figure 3. UV-Vis absorption spectra of the $\mathrm{Al}(\text { aind })_{3}\left(\mathrm{H}_{2} \mathrm{O}\right), \mathrm{Al}(\text { bind })_{3}\left(\mathrm{H}_{2} \mathrm{O}\right)$ and $\mathrm{Al}(\mathrm{mbind})_{3}\left(\mathrm{H}_{2} \mathrm{O}\right)$ complexes recorded in acetonitrile solutions $\left(1.0 \times 10^{-5} \mathrm{~mol} \mathrm{~L}^{-1}\right)$.

\section{Photoluminescence properties}

The photoluminescent properties of $\mathrm{Al}^{3+}$-(indandionate) complexes in the solid state were investigated based on steady state and time-resolved emission spectra recorded at room (ca. $298 \mathrm{~K}$ ) and liquid nitrogen (77 K) temperatures (Figures $4 \mathrm{a}$ and $4 \mathrm{~b}$ ), respectively. The steady state emission spectra are characterized by a broad band in the spectral range of $420-650 \mathrm{~nm}$, centered at ca. $500 \mathrm{~nm}$, which is confirmed by their green luminescence color. The emission band may be attributed to the $S_{1} \rightarrow S_{0}$ transition of $\pi \rightarrow \pi^{*}$ nature centered on the indandionate moiety. Furthermore, the energy band position is almost insensitive to changes in the acyl substituent group. Interestingly, the emission spectra of all $\mathrm{Al}^{3+}$-indandionate complexes show very similar profiles to that $\mathrm{Alq}_{3}$, which is considered as one of the most efficient electron transporting molecules in OLEDs. ${ }^{36}$ In addition, the planar structure of the acylindandionate ligands may contribute to $\pi-\pi$ intermolecular interactions, similar to that occurring in $\mathrm{Alq}_{3}$. These optical data suggest that $\mathrm{Al}^{3+}$-indandionate complexes can be used to act in OLEDs as both electron transporting layer and emissive layer.

It is worth mentioning that the emission spectra of the $\mathrm{Al}^{3+}$-indandionate complexes in the solid state also exhibit a weak shoulder at low energy, around $600 \mathrm{~nm}$, indicating that there is an additional luminescence decay process. Based on these data, the time-resolved emission spectra of the complexes were recorded to investigate the nature of luminescence phenomenon (Figure 4b). The emission spectra show that the fluorescence broad band at $500 \mathrm{~nm}$ (Figure 4a) decreases its intensity abruptly when the time delay is increased, while the emission band at around $600 \mathrm{~nm}$ remains with significant intensity. This suggests that the band located at low energy may be assigned to a phosphorescence $\left(\mathrm{T}_{1} \rightarrow \mathrm{S}_{0}\right)$ transition of indandionate ligands.

Photoluminescence spectra of the $\mathrm{Al}^{3+}$-indandionate complexes deposited as films exhibit similar spectral profiles to those for their respective complexes in the powder form, reinforcing that not all anhydrous complexes undergo decomposition during thermal evaporation.

\section{Electroluminescence properties}

Cyclic voltammetry (CV) curves for $\mathrm{Al}(\text { aind })_{3}\left(\mathrm{H}_{2} \mathrm{O}\right)$ complex, in SI section, Figure S5, show three irreversible cathodic peaks at $-1.31,-1.47$ and $-1.67 \mathrm{~V}$ in the negative region. For the $\mathrm{Al}(\text { bind })_{3}\left(\mathrm{H}_{2} \mathrm{O}\right)$ complex, quasireversible cathodic peaks can be observed at $-0.95,-1.27$ and $-1.66 \mathrm{~V}$, while for $\mathrm{Al}(\text { mbind) })_{3}$ complex $\mathrm{CV}$ curves exhibit 2 cathodic peaks at -1.39 and $-1.67 \mathrm{~V}$ in a more negative region than the $\mathrm{Al}(\text { bind })_{3}\left(\mathrm{H}_{2} \mathrm{O}\right)$ complex. The onset voltages of cathodic curves were determined using the procedure described by Ahmed et al. ${ }^{37}$ allowing the determination of the LUMO energy positions. In addition, 

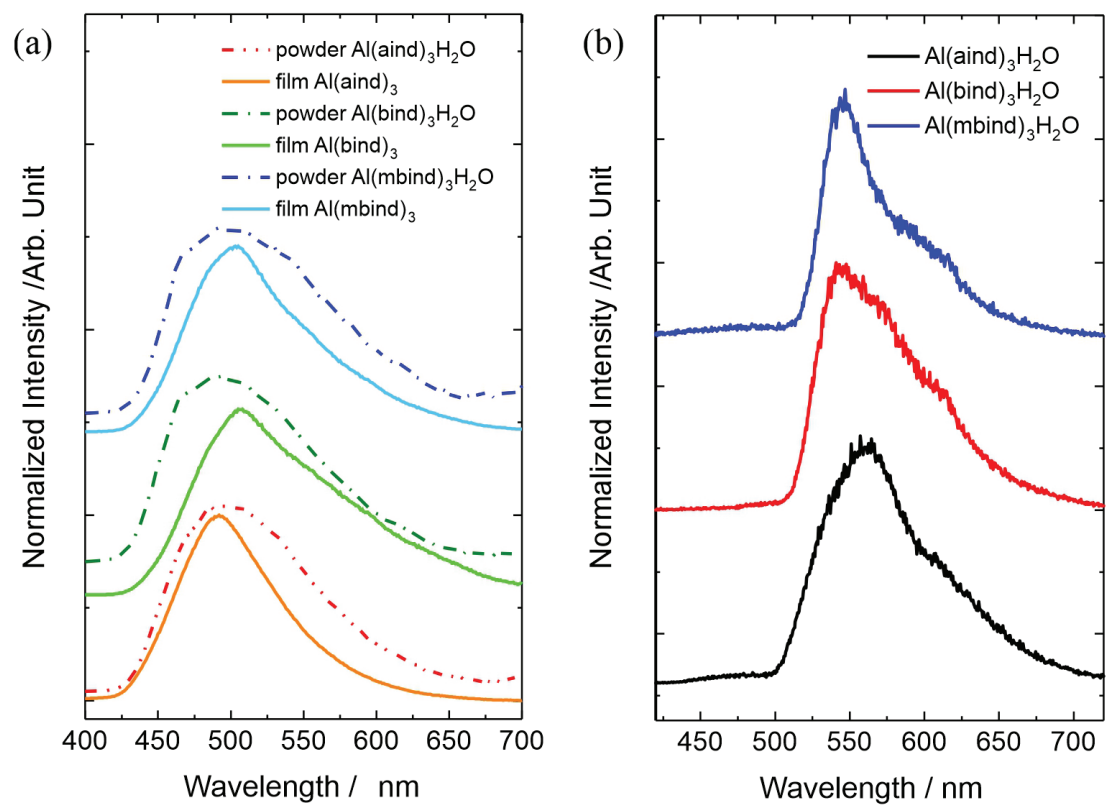

Figure 4. (a) Photoluminescence spectra of the complexes: $\mathrm{Al}(\text { aind })_{3}\left(\mathrm{H}_{2} \mathrm{O}\right), \mathrm{Al}(\text { bind })_{3}\left(\mathrm{H}_{2} \mathrm{O}\right)$, and $\mathrm{Al}(\mathrm{mbind})_{3}\left(\mathrm{H}_{2} \mathrm{O}\right)$ of the solid (powder state dash line) and thin film form (solid line) measured on steady state at $300 \mathrm{~K}$. (b) Time-resolved phosphorescence spectra of $\mathrm{Al}(\mathrm{aind})_{3}\left(\mathrm{H}_{2} \mathrm{O}\right), \mathrm{Al}(\mathrm{bind})_{3}\left(\mathrm{H}_{2} \mathrm{O}\right)$, and $\mathrm{Al}(\mathrm{mbind})_{3}\left(\mathrm{H}_{2} \mathrm{O}\right)$ complexes recorded at $77 \mathrm{~K}$, using time delay of $1 \mathrm{~ms}$.

the HOMO energy levels were then estimated by adding the optical band gap $\left(\mathrm{E}_{\mathrm{opt}}\right)$ to the LUMO levels, where $\mathrm{E}_{\mathrm{opt}}$ was obtained from the absorption spectra of the thin films. The energy gap and frontier orbital energies values

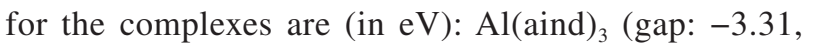
HOMO: -6.46 , and LUMO: -3.15 ); $\mathrm{Al}$ (bind) ${ }_{3}$ (gap: -3.82 , HOMO: -6.94 , and LUMO: -3.12 ) and $\mathrm{Al}(\mathrm{mbind})_{3}$ (gap: -3.36, HOMO: -6.54 , and LUMO: -3.18 ). These results reveal that both HOMO and LUMO energy levels are deeper than those for the Eu(acind $)_{3}(\text { tppo })_{2}$ complexes (where tppo is triphenylphosphine oxide). ${ }^{32}$ Generally, an error of about $0.5 \mathrm{eV}$ is estimated for HOMO and LUMO energies. However, in this work a relative comparison is made between the energy levels determined under the same conditions for all the molecules involved.

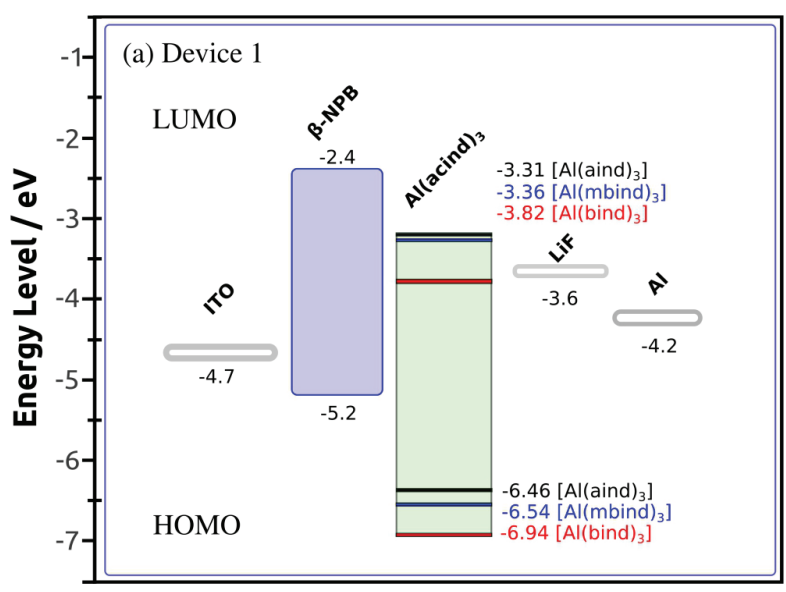

The rigid energy level diagrams for the device 1 and device 2 configurations (Figure 5) reflect the higher charge:radius ratio of the $\mathrm{Al}^{3+}$ ion, which contributes to a more pronounced polarizability of the coordinated ligands. Therefore, the $\mathrm{Al}^{3+}$-indandionate complexes tend to be less favorable to charge transport than similar $\mathrm{Ln}^{3+}$-indandionate complexes ( $\mathrm{Ln}: \mathrm{Eu}^{3+}$ and $\left.\mathrm{Gd}^{3+}\right)$.

Figure 6a shows the electroluminescence (EL) spectra of bilayer devices (1a, 1b, and 1c), with the LiF layer used to decrease the energy barrier between the $\mathrm{Al}$ electrode and LUMO levels. The EL spectra recorded at room temperature in range from 400 to $750 \mathrm{~nm}$ show a broad band at approximately $650 \mathrm{~nm}$, in which its emission intensities increase with the augmented applied voltage from 9 to $18 \mathrm{~V}$.

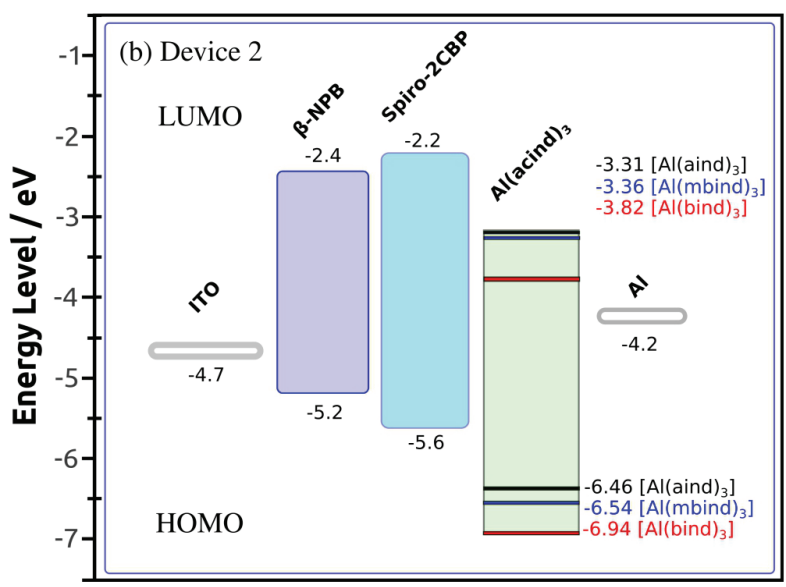

Figure 5. Rigid energy level diagrams for the fabricated OLEDs with device 1 (a) and device 2 (b) configurations. 
Different from the photoluminescence properties of these complexes in both powder and thin-film forms (Figure 4a) that exhibit strong green emission under photo-excitation, the correspondent electroluminescence devices $1 \mathrm{a}, 1 \mathrm{~b}$, and $1 \mathrm{c}$ exhibited a strong, broad, red emission band at $650 \mathrm{~nm}$ under electrical excitation. Thermal decomposition of the complexes on device fabrication can be eliminated, considering that both vibrational and emission spectra of the $\mathrm{Al}^{3+}$-indandionate thin films obtained from thermal evaporation show very similar spectral profiles to those for complexes in the powder forms (SI section, Figure S1). Based on the energy levels diagram for 1a, $1 \mathrm{~b}$ and 1c, the bilayer devices (Figure 5a) of all complexes presented HOMO and LUMO deeper than those for the $\beta$-NPB compound (HOMO: $-5.2 \mathrm{eV}$ and LUMO: $-2.4 \mathrm{eV}$ ). Accordingly, it is expected an intermolecular charge transfer from the LUMO level of the $\mathrm{Al}^{3+}$-indandionate complexes to the shallow HOMO level of the $\beta$-NPB, leading to an exciplex-based emission. In this case, the large charge separation distances in these devices may result in a small exchange energy, yielding a small $\Delta \mathrm{E}_{\mathrm{ST}}$ and an exciplex-type TADF. ${ }^{38}$ Furthermore, owing to the high energy barrier among the frontier orbitals of the complexes and of the $\beta-\mathrm{NPB}$, the electron and the hole may accumulate in the interfacial region, resulting in an appropriate exciplex formation process. It is noteworthy that the electroluminescence band is slightly red-shifted as compared to the phosphorescence band, reinforcing the observation that the exciplex emission is operative for 1a, $1 \mathrm{~b}$, and $1 \mathrm{c}$ bilayer devices. In addition, Figure 5 shows that the EL bands for 1a and 1c devices are broader than those ones for $1 b$ device, suggesting that methyl groups of the aind and mbind ligands play an important role on the exciplex-type recombination. This behavior may be owing to a more heterogeneous packing in the $\beta-\mathrm{NPB} / \mathrm{Al}(\text { acind })_{3}$ interfaces caused by bulky methyl substituent group.

It is noteworthy that the devices with the glass/ITO/ $\beta-\mathrm{NPB} /$ spiro-2CBP/[Al(acind) $\left.)_{3}\right] / \mathrm{Al}$ (2a, 2b, and $2 \mathrm{c}$ devices) configuration are characterized by the electroluminescence emission in the green region of the spectrum (Figure 6). Furthermore, the EL broad band spectral profiles are similar to those recorded for the photoluminescent (PL) ones from the $\mathrm{Al}^{3+}$-indandionate complexes in the powder and thinfilm forms. As observed from the energy level diagrams for $2 \mathrm{a}, 2 \mathrm{~b}$, and $2 \mathrm{c}$ devices (Figure $5 \mathrm{~b}$ ), the spiro-2CBP layer forms a barrier for electrons of $1.1 \mathrm{eV}$ and a lower barrier for holes $(0.8 \mathrm{eV})$. In this manner, we found formation of both singlet and triplet excitons in the emitting layer of the $\mathrm{Al}^{3+}$-indandionate complexes, leading to the green color emission (Figure 6).
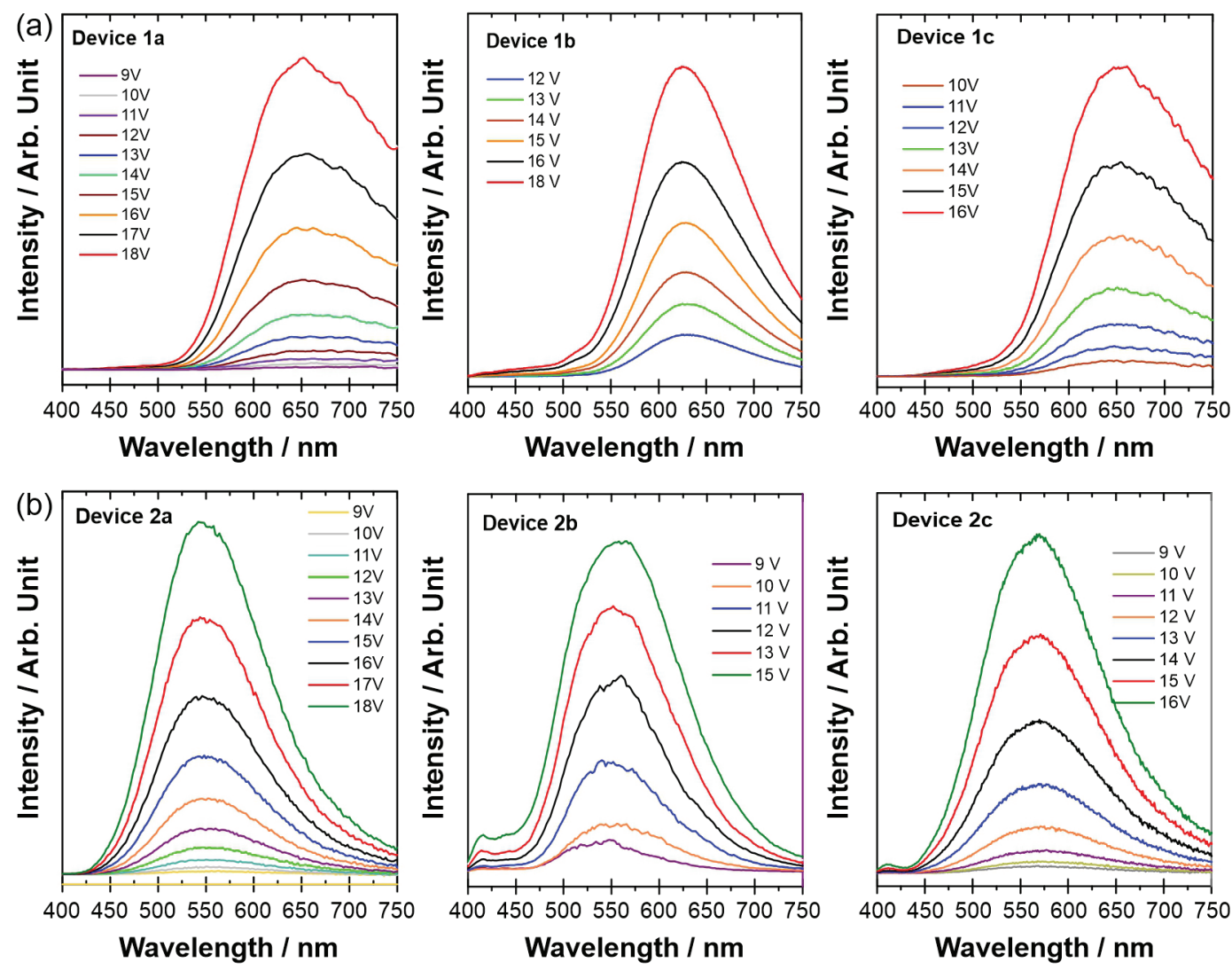

Figure 6. Electroluminescence spectra of (a) 1a, 1b, and 1c bilayer devices; (b) 2a, 2b, and 2c three-layer devices. 
No significant difference in the electroluminescent spectra of $2 a, 2 b$, and $2 c$ devices was observed. This optical result suggests that both PL and EL of the complexes are mainly centered on the 1,3-indandione moiety.

It is important to mention that $\mathrm{LiF}$ thin layer in $1 \mathrm{a}$, $1 \mathrm{~b}$, and $1 \mathrm{c}$ bilayer devices was used in order to decrease the driving voltage. In the absence of this layer, the devices with similar configurations (glass/ITO/NPB/ $\mathrm{Al}(\text { acind })_{3} / \mathrm{Al}$ ) present electroluminescence only at high driving voltages (SI section, Figure S6). However, these devices with or without the LiF layer exhibit similar red electroluminescence, indicating that the LiF plays a minor role in the electroluminescence mechanism in this kind of devices. On the other hand, the devices $2 a, 2 b$ and $2 c$ present electroluminescence at low driving voltage even without the $\mathrm{LiF}$ thin layer.

Figure 7 presents the CIE (International Commission on Illumination $)^{39}$ coordinates for $\mathrm{Al}^{3+}$-indandionate complexes-based devices. As can be observed, the CIE coordinates obtained for $1 \mathrm{a}, 1 \mathrm{~b}$, and $1 \mathrm{c}$ devices are found in the red region of the diagram; however, the $2 \mathrm{a}, 2 \mathrm{~b}$, and $2 \mathrm{c}$ devices are located in the green region.

As discussed earlier, the $1 \mathrm{a}, 1 \mathrm{~b}$, and $1 \mathrm{c}$ devices are driven by exciplex-type TADF mechanism, resulting in an EL red emission tuning color as compared with the PL of the complex, while the $2 \mathrm{a}, 2 \mathrm{~b}$, and $2 \mathrm{c}$ devices are driven by direct formation of singlet and triplet excitons in the emitting layer, yielding a green emission tuning color with

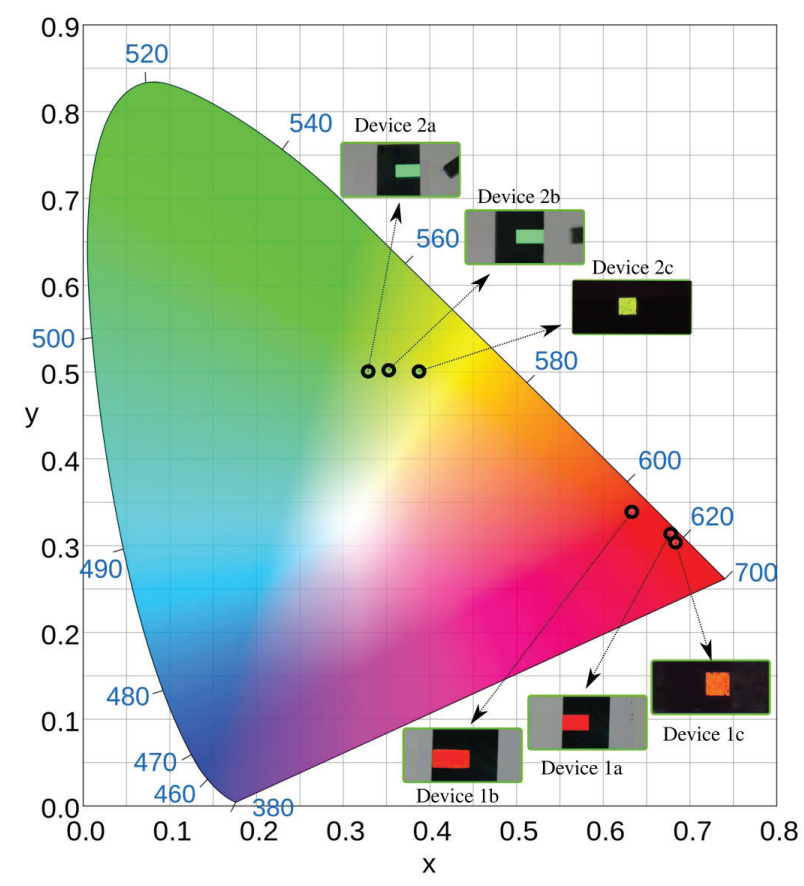

Figure 7. CIE chromaticity diagram presenting the (x, y) coordinates for the $\mathrm{Al}(\text { aind })_{3}, \mathrm{Al}$ (bind) $)_{3}$, and $\mathrm{Al}$ (mbind) $)_{3}$-based devices. Inset: the photograph of the fabricated OLEDs. similar coordination for the PL of the $\mathrm{Al}^{3+}$-indandionate complexes.

Although thin films for $\mathrm{Al}^{3+}$-indandionate and $\mathrm{Alq}_{3}$ coordination compounds present similar photoluminescent colors, their optoelectronic properties are quite different. This behavior may be explained based on the lowest energies of both HOMO and LUMO for $\mathrm{Al}^{3+}$-indandionate complexes as compared to those energies for $\mathrm{Alq}_{3}$ complex $(\mathrm{HOMO}=-5.6 \mathrm{eV}$ and $\mathrm{LUMO}=-2.3 \mathrm{eV})$.

Figure 8 shows the current density-voltage curves of all EL devices. According to these curves, the current densities increased exponentially with the increasing forward bias voltages, which are typically diode characteristics. Furthermore, the high threshold voltages around $8 \mathrm{~V}$ for both types of device configurations fabricated can be ascribed to the higher energy barrier for charge injection due to low energy of the frontier $\mathrm{HOMO}$ level of the $\mathrm{Al}^{3+}$-indandionate complexes from the ITO electrode and hole injection layer.

Regarding devices $1 \mathrm{a}, 1 \mathrm{~b}$ and $1 \mathrm{c}$, their structures induce space charge accumulation that increased the probability of exciplex-type recombination. This behavior is due to the high energy barrier of the LUMO ( $0.9 \mathrm{eV}$ for the electrons) and HOMO (1.2 eV for the holes) in the HTL/ETL interface together with the increase of electrons injection caused by the $\mathrm{LiF}$ presence. On the other hand, devices $2 \mathrm{a}, 2 \mathrm{~b}$ and $2 \mathrm{c}$ are observed in Figure 8 to be well-balanced, due to the insertion of spiro-2CBP layer which reduces the energy barrier for the holes $(0.8 \mathrm{eV})$ but still remaining for the electrons $(0.9 \mathrm{eV})$.

It is well known that the mobility of holes in $\beta$-NPB is 3 or 4 orders of magnitude greater than that of electrons in $\mathrm{Alq}_{3}$. Although no detailed information about electron mobility for $\mathrm{Al}(\text { acind })_{3}$ materials is known, the space charge accumulation must still be present in devices 2. However, this space charge accumulation controls the emission from the desired layer instead of increasing the probability of exciplex-type recombination. The reduction of less than half of the current density in devices 2, visible in Figure 8, is not only due to the increase of the devices' total thickness with insertion of the spiro-2CBP layer, but is also dependent on the energy level structure of the materials in these devices. Moreover, from the J vs. V (Figure 8) curves, when plotted on a log-log scale, both devices (with and without spiro-2CBP layer) probably present a space charge limited current type of behavior.

Figure 8 shows that the three-layer devices performed better than the bilayer devices. The maximum luminance achieved with $100 \mathrm{~mA} \mathrm{~cm}^{-2}$ of current density for device $2 \mathrm{a}$ was approximately $400 \mathrm{~cd} \mathrm{~m}^{-2}$, compared with approximately $10 \mathrm{~cd} \mathrm{~m}^{-2}$ for device 1a at the same current density value. Almost the same difference is observed between devices 1c and $2 \mathrm{c}$. This behavior may be related to a higher efficiency 
(a)

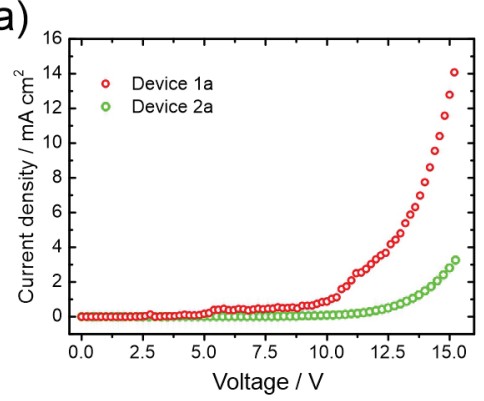

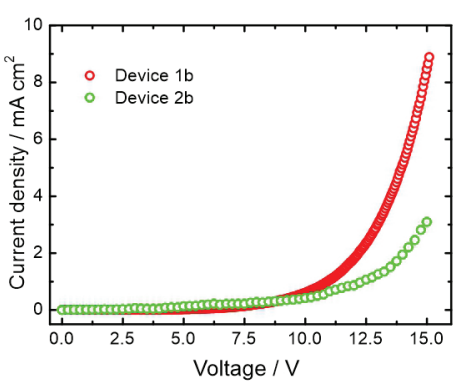

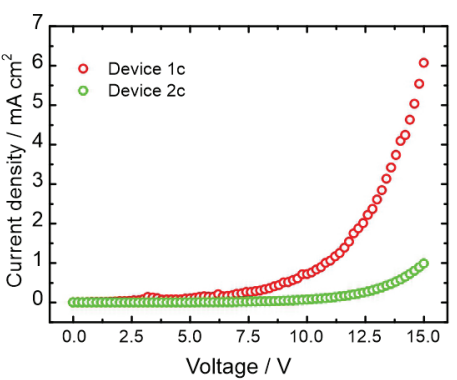

(b)

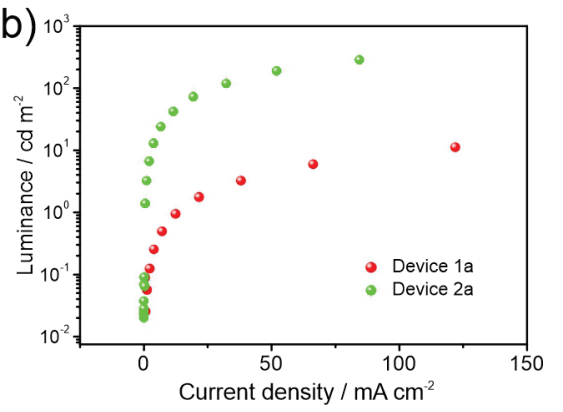

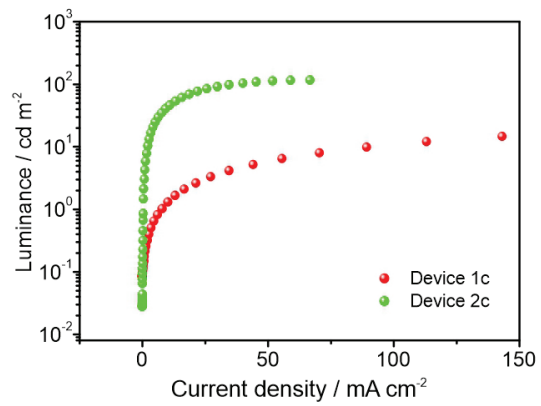

Figure 8. (a) Current density-voltage (J-V) characteristic curves of bilayer and three-layer devices. (b) Luminance-Current density (J-L) characteristic curves of the same devices. It was not possible to carry out the luminance response for device $2 b$ due to technical problems. However, it is expected that it would present similar behavior to devices $2 \mathrm{a}$ and $2 \mathrm{c}$.

in the transport and injection of holes due to the spiro-2CBP layer in devices $2 \mathrm{a}$ and $2 \mathrm{c}$, which reduced the energy hole barrier from 1.2 to $0.8 \mathrm{eV}$. Furthermore, the higher energies of the emitting states for devices $2 \mathrm{a}$ and $2 \mathrm{c}$ decreased nonradiative processes, leading to the higher electroluminescence intensities for these devices.

\section{Conclusions}

A novel type of strong photoluminescent $\mathrm{Al}^{3+}$ indandionate complexes was synthesized and used as the emitting layer in electroluminescent devices. It was demonstrated that the electroluminescent properties were strongly dependent on the device configurations. The glass/ITO/ $\beta$-NPB/[Al(acind) $\left.)_{3}\right] / \mathrm{LiF} / \mathrm{Al}$ devices showed strong red electroluminescence, while those of configuration glass/ITO/ $\beta-\mathrm{NPB} /$ spiro-2CBP/[Al(acind $\left.)_{3}\right] / \mathrm{Al}$ exhibited green emission colors. In addition, the fabricated devices exhibited tuning of the emission colors, suggesting that electroluminescent devices operate under different mechanisms. Based on the energy diagrams of molecular frontier orbitals, the electroluminescence properties of the glass/ITO/ $\beta$-NPB/spiro-2CBP/[Al(acind) 3$] / \mathrm{Al}$ devices arise from the direct charge combination in the $\mathrm{Al}^{3+}$-indandionate complexes used as emitting layers. On the other hand, the electroluminescence properties for glass/ITO/ $\beta-\mathrm{NPB} /\left[\mathrm{Al}(\text { acind })_{3}\right] / \mathrm{LiF} / \mathrm{Al}$ device arise due to exciplex-based emission, considering that the complexes and NPB act as acceptor and donor, respectively. These results provide a platform for developing novel materials for advanced optoelectronic applications.

\section{Supplementary Information}

FTIR, NMR and UV-Vis spectra, thermogravimetric and cyclic voltammetry supplementary data are available free of charge at http://jbcs.sbq.org.br as PDF file.

\section{Acknowledgments}

The authors thank the following Brazilian agencies for financial support: Conselho Nacional de Desenvolvimento Científico e Tecnológico (CNPq), PRONEX-FACEPECNPQ, INCT-INEO, and the Coordenação de Aperfeiçoamento de Pessoal de Nível Superior (CAPES).

\section{References}

1. Tang, C. W.; VanSlyke, S. A.; Appl. Phys. Lett. 1987, 51, 913.

2. Hung, W. Y.; Fang, G. C.; Lin, S. W.; Cheng, S. H.; Wong, K. T.; Kuo, T. Y.; Chou, P. T.; Sci. Rep. 2014, 4, 5161.

3. Kan, W.; Duan, C.; Sun, M.; Han, C.; Xu, H.; Chem. Mater. 2016, 28, 7145 .

4. Adamovich, V. I.; Cordero, S. R.; Djurovich, P. I.; Tamayo, A.; Thompson, M. E.; D'Andrade, B. W.; Forrest, S. R.; Org. Electron. 2003, 4, 77. 
5. Kulkarni, A. P.; Tonzola, C. J.; Babel, A.; Jenekhe, S. A.; Chem. Mater. 2004, 16, 4556.

6. Xu, H.; Chen, R.; Sun, Q.; Lai, W.; Su, Q.; Huang, W.; Liu, X.; Chem. Soc. Rev. 2014, 43, 3259.

7. Fan, C.; Yang, C.; Chem. Soc. Rev. 2014, 43, 6439.

8. Czerwieniec, R.; Yu, J.; Yersin, H.; Inorg. Chem. 2011, 50, 8293.

9. Kido, J.; Okamoto, Y.; Chem. Rev. 2002, 102, 2357.

10. Farinola, G. M.; Ragni, R.; Chem. Soc. Rev. 2011, 40, 3467.

11. Xu, H.; Sun, Q.; An, Z.; Wei, Y.; Liu, X.; Coord. Chem. Rev. 2015, 293, 228.

12. Reyes, R.; Cremona, M.; Teotonio, E. E. S.; Brito, H. F.; Malta, O. L.; J. Lumin. 2013, 134, 369.

13. Kalinowski, J.; Stampor, W.; Mężyk, J.; Cocchi, M.; Virgili, D.; Fattori, V.; di Marco, P.; Phys. Rev. B: Condens. Matter Mater. Phys. 2002, 66, 235321.

14. Kondakov, D. Y.; Pawlik, T. D.; Hatwar, T. K.; Spindler, J. P.; J. Appl. Phys. 2009, 106, 124510.

15. Bizzarri, C.; Hundemer, F.; Busch, J.; Bräse, S.; Polyhedron 2018, 140, 51.

16. Reineke, S.; Baldo, M. A.; Phys. Status Solidi A 2012, 209, 2341.

17. Adachi, C.; Jpn. J. Appl. Phys., Part 1 2014, 53, 060101.

18. Zhang, Q.; Li, B.; Huang, S.; Nomura, H.; Tanaka, H.; Adachi, C.; Nat. Photonics 2014, 8, 326.

19. Dias, F. B.; Penfold, T. J.; Monkman, A. P.; Methods Appl. Fluoresc. 2017, 5, 012001.

20. Penfold, T. J.; J. Phys. Chem. C 2015, 119, 13535.

21. Leitl, M. J.; Krylova, V. A.; Djurovich, P. I.; Thompson, M. E.; Yersin, H.; J. Am. Chem. Soc. 2014, 136, 16032.

22. Tao, Y.; Yuan, K.; Chen, T.; Xu, P.; Li, H.; Chen, R.; Huang, W.; Adv. Mater. 2014, 26, 7931.

23. Czerwieniec, R.; Leitl, M. J.; Homeier, H. H.; Yersin, H.; Coord. Chem. Rev. 2016, 325, 2.

24. Hofbeck, T.; Monkowius, U.; Yersin, H.; J. Am. Chem. Soc. 2015, 137, 399.

25. Wang, S.; Cheng, Z.; Song, X.; Yan, X.; Ye, K.; Liu, Y.; Yang, G.; Wang. Y.; ACS Appl. Mater. Interfaces 2017, 9, 9892.
26. Ahmedova, A.; Rusanov, V.; Hazell, A.; Wolny, J. A.; Gochev, G.; Trautwein, A. X.; Mitewa, M.; Inorg. Chim. Acta 2006, 359, 3123.

27. Ahmedova, A.; Marinova, P.; Ciattini, S.; Stoyanov, N.; Springborg, M.; Mitewa, M.; Struct. Chem. 2009, 20, 101.

28. Ahmedova, A.; Cador, O.; Sorace, L. Ciattini, S.; Gatteschi, D.; Mitewa, M.; J. Coord. Chem. 2008, 61, 3879.

29. Teotonio, E. E. S.; Brito, H. F.; Viertler, H.; Faustino, W. M.; Malta, O. L.; de Sá, G. F.; Felinto, M. C. F. C.; Santos, R. H. A.; Cremona, M.; Polyhedron 2006, 25, 3488.

30. Resende Filho, J. B. M.; Silva, J. C.; Vale, J. A.; Brito, H. F.; Faustino, W. M.; Espínola, J. G. P.; Felinto, M. C. F. C.; Teotonio, E. E. S.; J. Braz. Chem. Soc. 2014, 25, 2080.

31. Malina, I.; Kampars, V.; Belyakov, S.; Dyes Pigm. 2018, 159 , 655.

32. Teotonio, E. E. S.; Brito, H. F.; Cremona, M.; Quirino, W. G.; Legnani, C.; Felinto, M. C. F. C.; Opt. Mater. 2009, 32, 345.

33. Malina, I.; Kampars, V.; Turovska, B.; Belyakov, S.; Dyes Pigm. 2017, 139, 820.

34. Kilgore, L. B.; Ford, J. H.; Wolfe, W. C.; Ind. Eng. Chem. Res. 1942, 34, 494.

35. Santa-Cruz, P. A.; Teles, F. S.; SpectraLux Software, version 2.0; Ponto Quântico Nanodispositivos/RENAMI, Recife, PE, Brazil, 2003.

36. Tamao, K.; Uchida, M.; Izumizawa, T.; Furukawa, K.; Yamaguchi, S.; J. Am. Chem. Soc. 1996, 118, 11974.

37. Ahmed, Z.; Aderne, R. E.; Kai, J.; Chavarria, H. I. P.; Cremona, M.; Thin Solid Films 2016, 620, 34.

38. Sarma, M.; Wong, K. T.; ACS Appl. Mater. Interfaces 2018, 10, 19279.

39. Ono, Y. A.; Electroluminescent Displays; World Scientific: New Jersey, 1995.

Submitted: November 5, 2018

Published online: April 17, 2019 